\title{
Commentary on behavioral price research: the role of subjective experiences in price cognition
}

\author{
Manoj Thomas \\ Received: 27 February 2013 / Accepted: 1 March 2013 /Published online: 13 March 2013 \\ (C) Academy of Marketing Science 2013
}

How prices influence buyer behavior has been a topic of interest to several disparate groups of thinkers-businessmen seeking to maximize their profits, policy makers interested in securing and promoting consumer welfare, and academics interested in characterizing the cause-and-effect patterns in markets. As Cheng and Monroe (2013) note in their review of the pricing literature, the early academic thinking on prices was influenced largely by economics. However, several scholars have argued that models of price cognition inspired by economics lack realism because the economist's perspective on how buyers respond to prices was constrained by the premise of rationality and the tractability of mathematical models. Much like the advent of other allied disciplines such as behavioral economics and behavioral finance, the advent and proliferation of behavioral pricing research (or behavioral price research, as Cheng and Monroe 2013 prefer to call it) was triggered by a reactance to the lack of realism in the traditional economic models of pricing. Behavioral pricing scholars put greater emphasis on descriptive validity than on adherence to axioms of rational behavior. They focused on characterizing how buyers actually behave rather than on how a rational buyer ought to behave. Not surprisingly, early research on behavioral pricing put the spotlight on those phenomena that were at odds with the assumptions of the traditional economic models.

This historic context is useful in understanding and appreciating the contributions of Kent Monroe and other behavioral pricing scholars to the literature. Over the last few decades, behavioral pricing scholars have argued that contrary to the axioms of rational buyer behavior, buyers

\section{Thomas $(\bowtie)$}

S. C. Johnson Graduate School of Management,

Cornell University, 353 Sage Hall,

Ithaca, NY 14850, USA

e-mail: manojthomas@cornell.edu compare the price of a product to its historic price even when the historic price is completely irrelevant to the transaction, as demonstrated in the rich and growing literature on reference price effects. Scholars have delved into how reference prices are formed in consumer minds. They have examined when an offer price is assimilated to the reference price and when it is contrasted from the reference price and why gains and losses from reference prices elicit asymmetric responses from buyers. Behavioral pricing scholars have argued that buyers' subjective assessment of the utility from a product or a service is not always independent of its price; the two are often correlated as demonstrated in the extensive priceperceived quality literature. These and other such findings are now well accepted tenets of our knowledge base. That behavioral pricing research has had a major impact on scholarly thinking cannot be gainsaid. Even researchers who were not trained in this tradition or who were less favorably disposed to this line of research have, over the years, come to acknowledge and respect the empirical findings and the conceptual arguments presented in the behavioral pricing literature. Furthermore, the research methodology used by behavioral pricing researchers, namely laboratory experiments, has also gained greater legitimacy in the research community.

Our knowledge of price cognition has been substantially augmented by the constructs and conceptual frameworks from the numerical cognition literature. Monroe and Lee (1999) outlined the benefits that would accrue to theories of price cognition by considering the distinction between analog and symbolic representations of numbers and between implicit and explicit memory processes. Their suggestions have spurred a new sub-stream of research within behavioral pricing; the last decade has witnessed the publication of several empirical studies that use the principles of numerical cognition to identify new insights into how consumers evaluate prices (see Thomas and Morwitz 2009a for a recent review on this topic). 
My critique of Cheng and Monroe's (2013) review of the behavioral pricing literature focuses more on what they have omitted than on what they have said. In this commentary, I identify some gaps or unexplored domains in the behavioral pricing research landscape reviewed by Cheng and Monroe (2013), topics that I believe have received less attention than is due. In doing so, I argue that the field should transcend from being a "behavioral" branch of traditional pricing literature to the field of "Price Psychology" that is unfettered from the traditional view. Price psychology can be broadly defined as the study of how people's thoughts, feelings, and behaviors are influenced by the price of a product. In contrast, behavioral pricing has traditionally been fettered to the utility maximization perspective of buyer behavior. As a consequence, behavioral pricing has been somewhat oblivious to the roles of psychological factors such as subjective feelings, heuristics, goals, and mind-sets in everyday behavior. Recent advances in psychology, particularly in social psychology, cognitive psychology, and judgment and decision making, suggest that these factors-subjective feelings, heuristics, goals, and mind-sets - play very important roles in shaping everyday behavior. Delineating the roles of these factors can enhance the rigor as well as relevance of price psychology research.

Figure 1 presents a schematic depiction of the three approaches to studying the effect of price on consumer behavior. The traditional pricing approach, depicted in the first panel, posits that purchase decisions are based on the principle of rational utility maximization and people make tradeoffs between the utility from the product and the disutility from price. The behavioral pricing approach, depicted in the second panel, posits that purchase decisions are based

(a) The Utility Maximization Approach

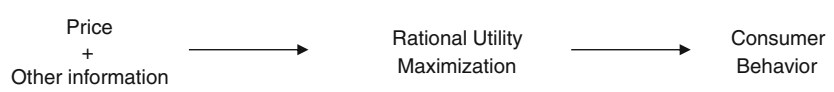

(b) The Behavioral Pricing Approach

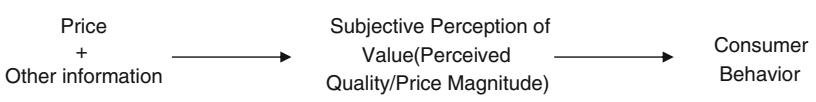

(c) The Price Psychology Approach

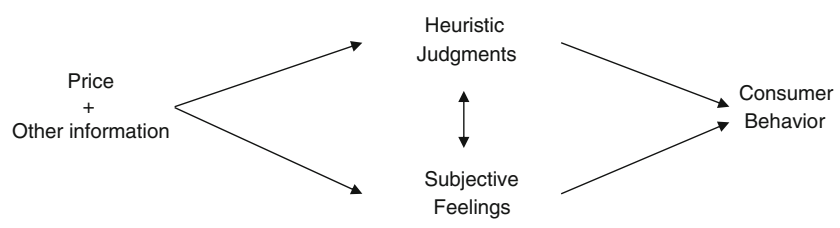

Fig. 1 a The utility maximization approach. b The behavioral pricing approach. c The price psychology approach on subjective assessments of value. People's assessments of value are influenced by subjective judgments of the magnitude of a price and the perceived quality of the offering. Behavioral pricing scholars have focused on characterizing how people judge the magnitude of a price and how they make quality assessments. The proposed price psychology approach, depicted in the third panel, posits that instead of focusing on subjective value as the key mediating variable in all purchase decisions, it might be more useful to focus on the different heuristics and feelings that guide purchase decisions. Consumers have different heuristics for different occasions. The heuristics used in a luxury retail store are quite different from those used in a grocery store. The heuristics used to evaluate store prices are different from the heuristics used to evaluate product prices. For example, when judging which of the two given stores offers lower prices, consumers relied on the frequency heuristic; that is, they used the frequency of discounts as a heuristic cue to identify the cheaper store (Alba et al. 1994). When judging how small or large the difference was between two prices, consumers relied on the left-digit anchoring heuristic (Thomas and Morwitz 2005) and the ease-ofcomputation heuristic (Thomas and Morwitz 2009b). Therefore, to accurately characterize a consumer's response to product price, researchers will have to delve into the context-dependent heuristic judgment strategies triggered by the stimuli and characterize the mechanisms that underlie these heuristics. A list of heuristics that consumers frequently use to evaluate price and a delineation of the underlying mechanisms will be very useful in offering a descriptive account of how consumers process prices.

\section{The role of subjective feelings}

Perhaps the most conspicuous omission in Cheng and Monroe's (2013) conceptualization is the role of subjective feelings in price evaluations. They briefly mention subjective feelings, but the fact that the discussion on the "emotional side of price" comes as an afterthought in the concluding paragraphs of their paper could be a reflection of the current mindset of pricing scholars. Economists dismiss subjective feelings as irrational and assume that rational people are immune to the influence of emotions (Rick and Loewenstein 2008). For a long time, even cognitive psychologists worked with the assumption they could study the process of thinking without concerning themselves with the experiential responses activated by thinking (LeDoux 1996). This view has changed in the recent past. More and more scholars agree that cognitive processes cannot be studied without studying the concomitant feelings. Based on a classification of the type of articles published in leading consumer research journals over a span of 25 years, Simonson et al. (2001) reported that there has 
been an increase in research articles that examine "hot" aspects of consumer decision such as affective experiences, arousal, and regret. Several scholars have suggested that there are transient cognitive feelings that last for only a fraction of a second, such as the feeling of fluency or the feeling of knowing as well as more intense emotional responses such as the pain of paying that influence consumers' evaluation of prices. I will illustrate this point with a few examples.

\section{The pain of paying}

Prelec and Loewenstein (1998) proposed that consumers experience "pain of paying" when they part with money. This pain of paying is a learned adaptive response that enables people to deal with everyday decisions. Consumers make purchase decisions by comparing the pleasure of consumption with the pain of payment. Several empirical studies provided support to the claim that pain of paying mediates the effect of price on consumers' responses. Knutson et al. (2007) examined how consumers respond to price while having their brains scanned with functional magnetic resonance imaging (fMRI). In this study, participants first saw the available product, then saw its price, and finally decided whether or not to purchase the product. The study revealed that excessive prices are associated with activation in the insula - a region known to be associated with pain. Moreover, activation in the insula was significantly greater for products that were ultimately not purchased than for products that were ultimately purchased. Based on these and other results, the authors concluded that the effect of price on purchase decisions is mediated by emotional responses in the brain.

The pain of paying is an idiosyncratic trait that can vary across individuals. Rick et al. (2008) developed a scale to measure individual differences in pain of payment and demonstrated that price framing effects (presenting a fee as "\$5 fee" versus "small $\$ 5$ fee") are stronger for tightwads who experience greater pain of payment than for spendthrifts. The pain of paying can also be influenced by contextual factors such as mode of payment. Thomas et al. (2011) demonstrated that abstract modes of payment, such as credit and debit cards, reduce the pain of payment and thus increase impulsive consumption. Moreover, the results suggested that pain of payment matters more when consumers rely on the affective responses to make purchase decisions. In their studies, pain of payment only influenced purchases of affect-laden vice products that are characterized by impulsive decisions and did not affect purchases of virtue products that are based on deliberative decisions.

\section{Cognitive feelings}

Cognitive feelings are the subjective experiences elicited by the cognitive processes. The feeling of ease/difficulty, the feeling of familiarity, and the feeling of knowing are some examples of cognitive feelings that influence our daily judgments. Unlike emotional states such as sadness or anger that can last for a long time, cognitive feelings are transient. That is, cognitive feelings last for less than fraction of a second and often escape conscious attention. Several scholars have suggested that cognitive feelings are an integral element of everyday judgments, so much so that it might not be feasible to offer a complete description of how people make everyday judgments without acknowledging the pivotal role of cognitive feelings. For example, Whittlesea (1993) argued that recognition judgments are based on the "feeling of familiarity," the subjective experience of ease that accompanies the encoding of a previously encountered stimulus. In a series of cleverly designed experiments, he demonstrated that processing fluency caused by perceptual factors (perceptual fluency) as well as conceptual factors (conceptual fluency) can cause feelings of familiarity and thus influence judgments of recognition. In fact, based on the results from his studies, Whittlesea (1993, p. 1248) argued that access of memory-based content is not necessary for recognition: "...feelings of familiarity are the product of an unconscious interpretive process that attributes fluent processing to a plausible source. This heuristic process appears not to have access either to the contents of memory or to the stimulus processing that is driven by memory."

In a similar vein, other psychologists have argued that the subjective "feeling of knowing" plays an important role in the monitoring of knowledge (Koriat 2007). The most cited finding in this stream of research is that even when people are unable to recall items from memory (for example, the answer to a general knowledge question), they have an intuitive feeling-of-knowing that they would be able to identify the correct answer in a recognition test. In related work, researchers have identified a tip-of-the-tongue state wherein people fail to recall a word or a name and yet have a feeling of knowing that they know the word and even sense its emergence into consciousness. Several studies have found that the intuitive feeling-of-knowing is diagnostic of the accuracy of responses in subsequent recognition tests (Koriat 2007). These studies tell us that subjective feelings are informative of the contents of our memory, even when we are unable to recall the information.

\section{Cognitive feelings and price evaluations}

Recent studies suggest that cognitive feelings also play an important role in price psychology. Thomas and Morwitz (2009a, b) have shown that, independent of the actual magnitude of numeric difference, processing fluency can influence judgments of price difference. The easier it is to compute the difference between two prices, the larger is the perceived difference between the two prices. For example, when 
presented with two pairs of numbers, participants in their experiments incorrectly judged the magnitude of the difference to be smaller for pairs with difficult computations (e.g., 4.97-3.96, an arithmetic difference of 1.01) than for pairs with easy computations (e.g., 5.00-4.00, an arithmetic difference of 1.00). The experiments were carefully designed to offer empirical evidence for the proposition that subjective feelings of ease or difficulty can influence judgments of price difference. As well, Bagchi and Davis (2012) suggested that processing fluency can influence how consumers integrate different types of numerical information in consumption contexts. Specifically, they found that when it is difficult to do computations, consumers do not integrate different pieces of numerical information and their evaluations tend to be anchored on the most salient numeric information.

\section{The feeling of knowing}

Another type of cognitive feeling that is relevant to price cognition is the feeling of knowing. The extant literature on the feeling-of-knowing can address a long-standing conundrum in the pricing literature. Evidence from multiple streams of research suggests that price comparisons can be and are often done nonconsciously, without recalling the comparison standard. Price recall surveys have shown that a majority of consumers are unable to correctly articulate the past prices of products, even seconds after selecting them (Dickson and Sawyer 1990; Le Boutillier et al. 1994; Monroe and Lee 1999). For example, Krishna et al. (1991) found that more than $40 \%$ of consumers were unable to provide a response when asked for the regular prices of products they frequently buy, and only $34 \%$ were correct within 20 cents of the actual price. However, econometric analysis of scanner panel data that captured consumer purchase decisions in retail stores painted a different picture. Such econometric studies have shown that small deviations from past prices, commonly termed "reference" prices, of grocery products can influence consumer purchase behavior (Briesch et al. 1997; Winer 1986; Kalyanaram and Winer 1995). In fact, Briesch et al. (1997) found that the reference price a consumer uses for memory-based comparisons is not some category level average or the price they paid the last time they bought the product; instead, consumers operate at the brand level. The results from the econometric analysis suggested that consumers are in some mysterious way able to retain the past price of each brand in their memory, even when they are unable to consciously recall these prices. In the words of Briesch et al. (1997, p. 213): "Even though storing the price histories of each brand in memory appears cognitively burdensome, the prices of different brands may be perceived by consumers to be distinctive enough to construct separate reference prices for each brand."
These findings raise the inevitable question for price cognition researchers: How can consumers encode and use the past prices of multiple brands in scores of categories for memory-based comparisons when they are unable to recall it? To account for this conundrum, scholars have suggested that explicit recall of a comparison standard may not be necessary to make magnitude judgments. Even when unable to articulate the past price, consumers might be able to judge whether a current price is lower or higher than that past price (Adaval and Monroe 2002; Monroe and Lee 1999; Thomas \& Morwitz 2009a, b; Vanhuele and Drèze 2002).

Adaval and Monroe (2002) offered direct empirical evidence for the proposition that memory-based price comparisons do not necessarily entail conscious recall of the reference price. They demonstrated that participants' price magnitude judgments were influenced by subliminally presented incidental anchors. Participants in one experiment were asked to evaluate the expensiveness of a camera priced at $\$ 69.99$. Before participants evaluated the camera, half of them were subliminally exposed to a low range of prices (\$15 to \$29) whereas the other half was exposed to a high range of prices ( $\$ 85$ to $\$ 99$ ). It is important to note that each price was presented only for 120 milliseconds and, therefore, the participants were not aware of the prime. Despite the lack of awareness, these primes influenced expensiveness judgments; participants exposed to the low price range evaluated the camera as being more expensive than those exposed to the high price range.

This finding, though very impressive, raises a fundamental question about the process of automatic magnitude comparisons. How do people trust their automatic response when they do not know the basis for their response? How do people know that they know the response to the price comparison question? I believe the intuitive feeling of knowing plays an important role in such automatic price comparisons. People rely on the feeling of knowing to assess the validity of their automatic magnitude judgments.

Memory-based magnitude comparisons, like other perceptual judgments, represent an instance where responses are based on intuitive feelings of knowing. For example, imagine sitting in a room lit by a 60 -watt light bulb. Shortly thereafter, you move to another room lit by a 30 -watt light bulb. Even without deliberative thinking, you could compare the lighting in the current room to the lighting you encountered in the previous room and know that the first bulb is brighter. Of the various possible responses in this memory-based comparison task (i.e., "the first bulb is brighter" "the second bulb is brighter," "both bulbs are equally bright"), you intuitively feel more confidence in the accuracy of the first response. Just as people can assess the relative brightness of light or the loudness of sound based on their intuitive feeling of knowing without deliberative thinking, they can also assess whether the magnitude 
of a number is small or large based on the feeling of knowing without relying on formal arithmetic thinking.

Kyung and Thomas (2013) used the Articulation Paradox to empirically support the claim that people rely on the feeling of knowing to assess the validity of their automatic magnitude judgments. They argue that if people rely on intuitive feeling of knowing to assess the accuracy of their judgment, then any factor that disrupts the intuitive feeling of knowing should reduce the accuracy of their judgments. Paradoxically, trying to consciously recall the reference price can disrupt the feeling of knowing and thus disrupt the accuracy of judgments. Results from several experiments supported this hypothesis. In the studies, participants were asked to compare the prices of several grocery products with the prices they had encountered previously. Half of them were asked to try to recall and articulate the reference price from memory before making the comparative judgment, while the other half did the comparisons without recalling the reference price from memory. As predicted, participants who attempted to articulate the reference price performed poorly in the comparison task. The authors show that this effect is mediated by the intuitive feeling of knowing, a type of cognitive feeling.

\section{Conclusion}

Cheng and Monroe (2013) offer a comprehensive review of the literature on behavioral pricing. They focus on subjective magnitude judgments and numerical cognition and characterize the subjective nature of these judgments. However, most of the studies reviewed are conspicuously silent on the role of subjective experience in price magnitude judgments. In this commentary, I have argued that subjective feelings, both mild cognitive feelings such as processing fluency and the feeling of knowing, as well as more intense emotional responses such as the pain of paying, play important roles in price psychology. Theoretical frameworks or models that do not incorporate the effects of such subjective feelings are likely to lack descriptive validity.

\section{References}

Adaval, R., \& Monroe, K. B. (2002). Automatic construction and use of contextual information for product and price evaluations. Journal of Consumer Research, 28(4), 572-588.

Alba, J. W., Broniarczyk, S. M., Shimp, T. A., \& Urbany, J. E. (1994). The influence of prior beliefs, frequency cues, and magnitude cues on consumers' perceptions of comparative price data. Journal of Consumer Research, 21, 219-235.

Bagchi, R., \& Davis, D. F. (2012). \$29 for 70 Items or 70 Items for $\$ 29$ ? How presentation order affects package perceptions. Journal of Consumer Research, 39(June), 62-73.
Briesch, R. A., Krishnamurthi, L., Mazumdar, T., \& Raj, S. P. (1997). A comparative analysis of reference price models. Journal of Consumer Research, 24(2), 202-214.

Cheng, L.L. \& Monroe, K.B. (2013). An appraisal of behavioral price research (Part I): Core concepts and numerical cognition. AMS Review. doi:10.1007/s13162-013-0041-1.

Dickson, P. R., \& Sawyer, A. G. (1990). The price knowledge and search of supermarket shoppers. Journal of Marketing, 54(3), $42-53$.

Kalyanaram, G., \& Winer, R. S. (1995). Empirical generalizations from reference price research. Marketing Science, 14(3), 161-169.

Knutson, B., Rick, S., Wimmer, G. E., Prelec, D., \& Loewenstein, G. (2007). Neural predictors of purchases. Neuron, 53, 147-156.

Koriat, A. (2007). Metacognition and consciousness. In P. D. Zelazo, M. Moscovitch, \& E. Thompson (Eds.), The Cambridge handbook of consciousness (pp. 289-325). Cambridge: Cambridge University Press.

Krishna, A., Currim, I. S., \& Shoemaker, R. W. (1991). Consumer perceptions of promotional activity. Journal of Marketing, 55(2), 4-16.

Kyung, E. \& Thomas, M. (2013). Knowing without remembering: How articulation reduces the accuracy of numeric comparisons. Johnson school working paper.

Le Boutillier, J., Le Boutillier, S. S., \& Neslin, S. A. (1994). A replication and extension of the Dickson and Sawyer PriceAwareness Study. Marketing Letters, 5(1), 31-42.

LeDoux, J. (1996). The emotional brain: The mysterious underpinnings of emotional life. New York: Touchstone.

Monroe, K. B., \& Lee, A. V. (1999). Remembering versus knowing: issues in buyers' processing of price information. Journal of the Academy of Marketing Science, 27(2), 207-225.

Prelec, D. \& Loewenstein G. (1998). The red and the black: mental accounting of savings and debt. Marketing Science, 17(1), 4-28.

Rick, S., \& Loewenstein, G. (2008). The role of emotion in economic behavior. In M. Lewis, J. Haviland-Jones, \& L. Feldman-Barrett (Eds.), The handbook of emotion (3rd ed., pp. 138-156). New York: Guilford.

Rick, S., Cryder, C., \& Loewenstein, G. (2008). Tightwads and spendthrifts. Journal of Consumer Research, 34(6), 767-782.

Simonson, I., Carmon, Z., Dhar, R., Drolet, A., \& Nowlis, S. M. (2001). Consumer research: in search of identity. Annual Review of Psychology, 52, 249-275.

Thomas, M. \& Morwitz, V. (2009b). Heuristics in numerical cognition: Implications for pricing. In V. Rao, (ed.), Handbook of research in pricing (pp. 132-149). Northampton, MA: Edward Elgar Publishing.

Thomas, M., \& Morwitz, V. (2005). Penny wise and pound foolish: the left digit effect in price cognition. Journal of Consumer Research, $32,54-64$.

Thomas, M., \& Morwitz, V. (2009). The ease of computation effect: the interplay of metacognitive experiences and naïve theories in judgments of price difference. Journal of Marketing Research, 46, $81-91$.

Thomas, M., Desai, K., \& Seenivasan, S. (2011). How credit card payments increase unhealthy food purchases: visceral regulation of vices. Journal of Consumer Research, 38(1), 126-139.

Vanhuele, M., \& Drèze, X. (2002). Measuring the price knowledge shoppers bring to the store. Journal of Marketing, 66(4), 72-85.

Whittlesea, B.W.A. (1993). Illusions of familiarity. Journal of Experimental Psychology: Learning, Memory, and Cognition, 19, $1235-1253$.

Winer, R.S. (1986). A reference price model of brand choice for frequently purchased products. Journal of Consumer Research $13,250-256$ 